COMMENTARY

\section{The Problem with Breastfeeding Discourse}

\author{
Stephanie J. Knaak, PhD Candidate
}

\section{ABSTRACT}

This paper reflects on how informational biases have subtly entered into the breastfeeding health discourse and recommends how focus might be redirected. Specifically, contemporary infant feeding health discourse reflects a biased representation of the scientific literature, and fails to provide an appropriate contextualization of risk and benefit. It is important to correct these biases in order to uphold the foundational ethics of expert-guided childcare, and to rightly reposition the discourse as a tool for influence via education, not informational manipulation. Correcting these biases would also ease the discursive pressure and associated emotional burdens mothers currently experience in relation to infant feeding, and would reinforce a needed commitment to the development of appropriate supports to help mothers viably exercise their right to breastfeed.

MeSH terms: Breastfeeding; ethics; health promotion; health education; public health practice

\section{RÉSUMÉ}

Cet article est une réflexion sur l'insinuation de biais d'information dans le discours sur les bienfaits de l'allaitement pour la santé; nous recommandons aussi des moyens de réorienter ce discours. Plus précisément, le discours actuel sur la saine alimentation du nourrisson brosse un portrait tendancieux des publications scientifiques et n'offre pas une mise en contexte suffisante des risques et des avantages de l'allaitement. Il est important de corriger ces biais pour confirmer le fondement moral $d^{\prime}$ 'une puériculture fondée sur les conseils d'experts et pour faire du discours ce qu'il devrait être, c'est-à-dire un outil d'influence par la sensibilisation et non un exercice de manipulation de l'information. La correction de ces biais soulagerait aussi la pression exercée par le discours actuel et le fardeau psychologique subi par les mères en ce qui a trait à l'alimentation de leur nourrisson. Cela renforcerait un engagement nécessaire en faveur de l'élaboration de supports appropriés pour aider les mères à exercer dans la pratique leur droit d'allaiter.
Department of Sociology, University of Alberta, Edmonton, AB T6G 2H4, Tel: 780-492-0481, Fax: 780-492-7196, E-mail: sknaak@ualberta.ca
$\mathrm{B}$ reastfeeding education has been an important focus in recent years. Largely, efforts have proven successful. Over $85 \%$ of Canadian mothers breastfeed (compared to two thirds in the 1980s), the majority for longer than three months. ${ }^{1-3}$ Among university-educated mothers, 95\% breastfeed. ${ }^{1}$ However, the news is not all good. Initiation and duration rates are substantially lower among mothers with lower income and education, as well as among younger mothers, single mothers, and mothers from certain geographic regions, such as Atlantic Canada. ${ }^{2,4}$ In general, the mothers least likely to breastfeed are those with insufficient resources in terms of time, energy, material and social support. Furthermore, mothers' infant feeding experiences are becoming increasingly fraught with emotional burdens, including anxiety, frustration, guilt, feelings of failure, and worry about living up to the standard of "good motherhood". 5-7

These issues implicate breastfeeding advocacy in two ways. First, the demographic variability suggests that the primary issue is not that of a lack of education mothers are aware that "breast is best" and the vast majority intend to breastfeed but of a lack of necessary resources to successfully undertake the work of breastfeeding. ${ }^{8-10}$ Second, the discourse itself has become problematic. The educational and promotional literature has become biased, making it more a tool for persuasion than a tool for education. And it is this - a concern with the current state of the discourse - that commands the primary focus of this commentary.

\section{Are we educating or advertising?}

Health discourses enjoy a privileged status in today's society. They are known for providing impartial, scientifically sound, trustworthy knowledge. As such, they carry the responsibility for providing the "best" or most truthful information available. In this vein, pro-breastfeeding health discourse is the primary educator of infant feeding alternatives and the inherent value of breastfeeding. It also provides a crucial counter-discourse to formula producers' advertising savvy, political influence, and self-serving manipulation of knowledge. ${ }^{11}$ Equally as important, breastfeeding health discourse aims to allay cultural myths about breast- and formula feeding that 
contribute to a still-existent cultural resistance towards mothers' right to breastfeed "anywhere, anytime."12 Last, contemporary infant feeding health discourse has been shaped by practice. It has been influenced by a concern that mothers' breastfeeding intentions may be undermined if they perceive it to be unpleasant, or if they perceive formula to be of equivalent nutritional quality.

These influences have all helped give shape to the current state of infant feeding health discourse - a largely oppositional discourse characterized by an ever-widening gap between the ideal of breastfeeding and the acceptability of formula as an alternative. ${ }^{13}$ Occurring mainly through a process of inappropriate "scientific selectivity," this discourse reflects a biased representation of the scientific literature, and problematically fails to provide an appropriate contextualization of risk and benefit.

For one, much of the research finding its way into the educational and promotional discourse shows significant health advantages associated with breastmilk. Those studies showing little or no relationship are given less, if any, notice. Take, for example, the claim that breastfeeding enhances cognitive development and IQ. ${ }^{1}$ While considerable reference is made to research in support of this view, there is little acknowledgement that most higher-quality studies find no significant relationship between method of infant feeding and IQ or cognitive development. ${ }^{14,15}$ Another way that "scientific selectivity" occurs is by giving credence to studies that fail to properly control for major confounding influences, such as socio-economic status. ${ }^{16,17}$ Such studies are really demonstrating the significance of socio-economic status on differences in health - not the incremental benefits of breastfeeding. ${ }^{4,18}$

Selectivity also occurs when communicating the risks of formula feeding - especially mortality and serious morbidity - by primarily referencing global epidemiological studies. ${ }^{19}$ As these studies generally include data from countries with poor sanitation and clean water access, they are unsuitable for the assessment of risk in the Canadian context. ${ }^{20}$ In general, there is a failure to appropriately contextualize risk and benefit. For example, in focussing so much on why formula is a poor substitute for breastmilk, a contextualization of the relative magnitude of these differences in comparison to the risk of feeding something other than formula or breastmilk often gets missed. ${ }^{17,21}$

Last, there is a tendency to frame potentially pleasurable aspects of breastfeeding as intrinsic to the experience itself. Two of the most common arguments are that breastfeeding is pleasurable because it is convenient, and better promotes mother/ baby attachment. ${ }^{22}$ Problematically, these assertions are often not accompanied by citations, suggesting they may be driven more by ideology. For example, the following statement in a Health Canada report provides citations for only the first two claims: "there are numerous benefits from breastfeeding, including protection against infectious diseases, healthy development of the brain and nervous system, and improved bonding between mother and child." Importantly, there are data on the subject of mothers' breastfeeding experiences, and these tell us that breastfeeding is not necessarily convenient or relationshipenhancing. Rather, experiences vary, from pleasurable, to burdensome, to ambivalent. ${ }^{5-8,23,24}$

\section{Discursive consequences and pro- posed solutions}

In addition to many positive consequences - like increased breastfeeding rates, and a commitment among many mothers (especially those with sufficient resources) to make breastfeeding work - there are serious problems with this discursive trend. For one, the pressure mothers experience in relation to breastfeeding becomes much greater, and the emotional consequences of not breastfeeding (or of not breastfeeding exclusively or for a long enough duration) become more severe. ${ }^{25,26}$ This discursive pressure is a notable source of mothers' emotional burdens with infant feeding. ${ }^{22,27}$

Second, in failing to openly discuss the complete range of experiences associated with breastfeeding, we risk propagating idealized motherhood myths - myths that fail to adequately embrace the often difficult and unpleasant work of infant feeding. Being forthright about the variability of experiences is thus an important discursive change to make. Not only would it be more reflective of the current state of the literature, it would validate the normalcy of the ambivalent aspects of mothers' experiences.
Third, the foundational ethics of expertguided childcare are being undermined by biased discourse. Mothers empower health professionals by seeking out their knowledge and expertise. Health professionals, in turn, empower mothers by respecting their decision-making autonomy. The lynchpin of this relationship is the communication of scientifically-sound, impartial information. When the information becomes biased, the discourse takes on a manipulative character, threatening the foundation of trust so central to this relationship. ${ }^{28}$

The current state of breastfeeding discourse thus represents a serious ethical issue. In order to correct this problem, the main criterion for selectivity should, in all instances, be the use of only high-quality studies. This means: being vigilant about methodological rigor, especially in regards to sample quality and the control of confounding variables; and being aware of political or ideological investments in the research. ${ }^{29,30}$ Proper selectivity also means making use of the full spectrum of available research, and ensuring it is contextually applicable.

The other important change required to the dominant discourse is a better contextualization of the relative risks and benefits of infant feeding alternatives. Communicating the various statistics of risk associated with formula- and breastfeeding is necessary, but so is ensuring a proper articulation of the safety margins. ${ }^{31}$ It is also important to situate the relative health impacts of infant feeding within a broader context of risk. For example, how significant to overall health is the quality of a child's solid food diet in comparison to their infant diet? What ultimately presents a bigger risk for respiratory infection exposure to viruses (perhaps through a school-age sibling) or formula feeding? And how significant is a respiratory infection to overall infant health in relation to other health concerns, such as accidents for example? Incorporating this kind of broader contextual recognition into the discourse will allow mothers to better evaluate the relative significance of their infant feeding decisions in relation to their many other health and mothering considerations.

\section{Improved programming support}

Attending to these discursive changes may risk negatively affecting breastfeeding 
intentions. However, it is a risk that must be embraced to uphold the ethical principles upon which the discourse operates, and to rightly reposition it as a tool for influence via education, not informational manipulation. ${ }^{28}$ Making these changes would also ease many of the emotional burdens to which the discourse currently contributes.

While these changes could diminish the discourse's persuasive power, the potential corollary is that it would encourage a greater commitment to developing supports to make breastfeeding more feasible for all mothers. ${ }^{32,33}$ It is instructive that the developed countries with the highest breastfeeding rates are also more likely to have official "baby-friendly" maternity hospitals (Canada has only six hospitals and health centres that have been endorsed according to the WHO/Unicef BabyFriendly Hospital Initiative), ${ }^{34}$ more generous maternity leave policies, and higher levels of supports for low-income mothers. ${ }^{35,36}$ In this vein, we should be aiming to achieve official baby-friendly status for all Canadian hospitals/health centres; enhancing community supports for breastfeeding - perhaps using postpartum doulas - especially for resource-poor mothers; improving education to partners/fathers about mothers' support needs and their significance to breastfeeding success; and improving cultural outreach about mothers' breastfeeding rights. ${ }^{10,37,38}$ It is this combination of efforts - correcting discursive biases, and improving breastfeeding supports - that will best ensure mothers' infant feeding experiences are as positive and healthful as possible, and that breastfeeding initiation and duration rates continue to rise.

\section{REFERENCES}

1. Health Canada. Toward a Healthy Future: Second Report on the Health of Canadians. Ottawa, ON: Author, 1999.
2. Millar WJ, Maclean H. Breastfeeding practices. Health Reports 2005;16(2):23-31

3. Statistics Canada. Health indicators. Ottawa: Statistics Canada. Cat. No. 82-3221-XIE, 2001. Available online at: www.statcan.ca (Accessed January 15,2003$)$.

4. Dennis CL. Breastfeeding initiation and duration: A 1990-2000 literature review. JOGNN 2002;31(1):12-32.

5. Maclean H. Women's Experience of Breast Feeding. Toronto, ON: University of Toronto Press, 1990.

6. Schmeid V, Barclay L. Connection and pleasure, disruption and distress: Women's experiences of breastfeeding. J Hum Lact 1999;15(4):325-33.

7. Davies L. Breastfeeding, motherhood and maternal health. Paper presented at the Association for Research on Mothering's Mothering and Feminism conference, October 22-24, 2004. York University, Toronto, Ontario.

8. Murphy E. "Breast is best": Infant feeding decisions and maternal deviance. Sociol Health Illnes 1999;21(2):187-208.

9. Anderson ES, Jackson A, Wailoo MP, Petersen SA. Child care decisions: Parental choice or chance? Child: Care, Health \& Development 2002;28(5):391-401.

10. Earle $S$. Why some women do not breastfeed: Bottle feeding and father's role. Midwifery 2000;16:323-30.

11. Van Esterik P. The politics of breastfeeding: An advocacy perspective. In: Van Esterik P, Counihan C (Eds.), Food and Culture: A Reader. New York, NY: Routledge, 1997;370-83.

12. Stearns C. Breastfeeding and the good maternal body. Gender \& Society 1999;13(3).

13. Knaak S. Breastfeeding, bottle feeding and Dr. Spock: The shifting context of choice. Can Rev Sociol Anthropol 2005;42(2):197-216.

14. Jain A, Concato J, Leventhal JM. How good is the evidence linking breastfeeding and intelligence? Pediatrics 2002;109(6):1044-53.

15. Anderson JW, Johnstone B, Remley D. Breastfeeding and cognitive development. Am J Clin Nutr 1999;70:525-35.

16. Bauchner H, Leventhal J, Shapiro ED. Studies of breastfeeding and infections: How good is the evidence? JAMA 1986;256(7):887-92.

17. Law J. The politics of breastfeeding: Assessing risk, dividing labor. Signs 2000;25(2):407-49

18. Newton ER. The epidemiology of breastfeeding. Clin Obstet Gynecol 2004;47(3):613-23.

19. INFACT Canada. Fourteen risks of formula feeding: A brief annotated bibliography. Toronto, Canada: Author, November 2002 Available online at: www.infactcanada.ca/factsheets.htm (Accessed March 2005)

20. Kramer MS, Chalmers B, Hodnett ED, Sevkovskaya Z, Dzikovich I, Shapiro S, et al Promotion of Breastfeeding Intervention Trial (PROBIT). A randomized trial in the Republic of Belarus. JAMA 2001;285(4):413-20.

21. Wolf J. Don't Kill Your Baby: Public Health and the Decline of Breastfeeding in the Nineteenth and Twentieth Centuries. Columbus, $\mathrm{OH}$ : Ohio State University Press, 2001.
22. Knaak S. Deconstructing discourse: Breastfeeding, intensive mothering and the moral construction of choice. Paper presented at the Annual Meetings of the Canadian Sociology and Anthropology Association, University of Toronto, May 29-31, 2002.

23. Schmied V, Lupton D. Blurring the boundaries: Breastfeeding and maternal subjectivity. Sociol Health Illness 1990;23(2):234-50.

24. Blum L. At the Breast: Ideologies of Motherhood and Breastfeeding in the Contemporary United States. Boston, MA: Beacon Press, 1999.

25. Murphy E. Risk, responsibility and rhetoric. J Contemporary Ethnography 2000;29(3):291-325.

26. Schmeid V, Sheehan A, Barclay L. Contemporary breast-feeding policy and practice: Implications for midwives. Midwifery 2001;17:44-54.

27. Wall G. Moral constructions of motherhood in breastfeeding discourse. Gender \& Society 2001;15(4):592-610.

28. Faden RR. Ethical issues in government sponsored public health campaigns. Health Educ $Q$ 1987;14(1):27-38.

29. Altman DG. Poor quality medical research: What can journals do? JAMA 2002;287(21):2765-67.

30. Associated Press. Take medical news with grain of salt, prestigious journal advises. Edmonton Journal, June 5, 2002: A5

31. Lupton D. Risk as moral danger: The social and political functions of risk in public health. Int Health Services 1993;23(3):425-35.

32. McIntyre E, Hiller J, Turnbull D. Determinants of infant feeding practices in a low socio-economic area: Identifying environmental barriers to breastfeeding. Austr $N Z$ I Public Health 1999;23(2):207-8.

33. Nolan L, Goel V. Sociodemographic factors related to breastfeeding in Ontario: Results from the Ontario Health Survey. Can J Public Health 1995;86(5):309-12.

34. Breastfeeding Committee of Canada. "Babyfriendly hospitals and birthing centres." May 2006. Available online at: www.breastfeedingcanada.ca (Accessed July 11, 2006).

35. Hofvander Y. Why women don't breastfeed: A national survey. Acta Paediatr 2003;92:1243-44.

36. Callen J, Pinelli J. Incidence and duration of breastfeeding for term infants in Canada, United States, Europe, and Australia: A literature review. Birth 2004;31(4):285-92.

37. Kessler L, Gielen AC, Diener-West M, Paige D. The effect of a woman's significant other on her breastfeeding decision. J Hum Lact 1995;11(2):103-8.

38. Bourgoin GL, Lahaie NR, Rheaume BA, Berger MG, Dovigi CV, Picard LM, Sahai VF. Factors influencing the duration of breastfeeding in the Sudbury region. Can J Public Health 1997;88(4):238-41

Received: May 16, 2005

Accepted: January 27, 2006 